\title{
Epidemiology of cryptonisci (Bopyridae: Isopoda) in the Gulf of Carpentaria, Australia
}

\author{
L. Owens ${ }^{1}$, P. C. Rothlisberg ${ }^{2}$ \\ ${ }^{1}$ Department of Biomedical and Tropical Veterinary Sciences, James Cook University of North Queensland, Townsville, \\ Queensland 4811, Australia \\ ${ }^{2}$ CSIRO Marine Laboratories, Division of Fisheries, PO Box 120, Cleveland, Queensland 4163, Australia
}

\begin{abstract}
Three Gulf-wide cruises were examined for cryptonisci and the data analysed for the effect of environmental variables on cryptoniscid abundance. Location, season and location-season interaction accounted for $80 \%$ of the variability, with each accounting for 65,25 and $10 \%$ of the explained variability respectively. More cryptonisci were found offshore in the northern and northwestern areas of the Gulf and autumn had the highest abundance. In decreasing order, depth, temperature, salinity, light and their interactions were components within season and location and they accounted for $13,6,6,4$ and $43 \%$ of the variability respectively. The depth effect was related to the main prawn host Penaeus semisulcatus which also had a preference for deeper water. Fourteen different copepod intermediate hosts were identified by direct observation of attached cryptonisci, Canthocalanus pauper and Paraeuchaeta concinna were the most important. Environment, however, was more important than intermediate hosts in explaining variation in cryptoniscid numbers
\end{abstract}

KEY WORDS: Bopyrid Plankton · Environment

\section{INTRODUCTION}

The life cycle of bopyrid isopods involves an epicaridium larva which is released from the marsupium of the female bopyrid when the host prawn moults. The lecithotrophic larvae are positively phototactic and swim near the surface until they encounter a calanoid copepod to which they attach. The epicaridium metamorphoses via a moult into a microniscus which then develops into a cryptoniscus (Anderson \& Dale 1981). The cryptoniscus then detaches and searches for a postlarval prawn as a definitive host (Beck 1980). The planktonic phase probably takes between $10 \mathrm{~d}$ (Anderson \& Dale 1981) and 1 mo (Caroli 1928) depending on the bopyrid species and possibly the environmental factors.

To understand why adult bopyrids are distributed patchily, an understanding of the dispersal capabilities of the infective stage, the cryptoniscus, is needed. Beck (1979) suggested cryptonisci of Probopyrus pandalicola were capable of swimming $13 \mathrm{~km}$ from the habitat of their immediate host, Acartia tonsa, to the nursery ground of Palaemonetes paludosus where infection took place. Owens \& Rothlisberg (1991) described the vertical migration of bopyrid cryptonisci in the Gulf of Carpentaria, Australia, and estimated the advection distance of the larvae. That study suggested that cryptonisci were concentrated within $100 \mathrm{~km}$ of major foci of adult bopyrid infection. This study examined the geographic spread of cryptonisci within the Gulf of Carpentaria and the influence of environmental factors.

In the Gulf of Carpentaria, over $97 \%$ of adult bopyrid isopods found on commercial penaeid prawns were Epipenaeon ingens Nobili and $2 \%$ were Parapenaeon expansus Bourdon (in Owens \& Glazebrook 1985). In this region, these 2 members of the Orbioninae usually infect only 3 prawn species: Penaeus semisulcatus de Haan, $P$. merguiensis de Man and $P$. indicus Milne Edwards. Other members of the Bopyridae exist in the Gulf but they are not recorded often. It is assumed that the great majority of cryptonisci encountered will be $E$. ingens. 


\section{MATERIALS AND METHODS}

A maximum of 73 samples from each of 3 Gulf-wide cruises (Fig. 1) were sorted on a Bogorov tray under a dissecting microscope. The cruises were selected to give the widest possible spread of environmental parameters. June-July 1976 represented the coolest period (winter), January 1977 represented the hottest months (summer), and March 1977 (autumn) was chosen because of the low salinities associated with the rainy season. Counts of cryptonisci from 1 stepped, oblique net $(142 \mu \mathrm{m})$ tow at each site were standardised (no. $\mathrm{m}^{-2}$ ) for the depth and volume of water filtered. Data analysis was conducted on a DEC10 computer using the statistical packages GLIM and SPSSX. To see if data fitted certain statistical distributions (normal and Poisson), a Kolmogorov-Smirnov test was conducted on variables. Non-normally distributed variables were $\log _{10}+1$ transformed and retested. Poisson-distributed variables were transformed by a square root transformation. Copepod species and abundance were obtained from the same samples reported in Othman (1986). A multiple regression analysis was used to correlate copepod intermediate host numbers with cryptonisci. Initially, copepod species showing either negative or nonsignificant simple correlation coefficients with cryptoniscid numbers were eliminated as being unlikely intermediate hosts.

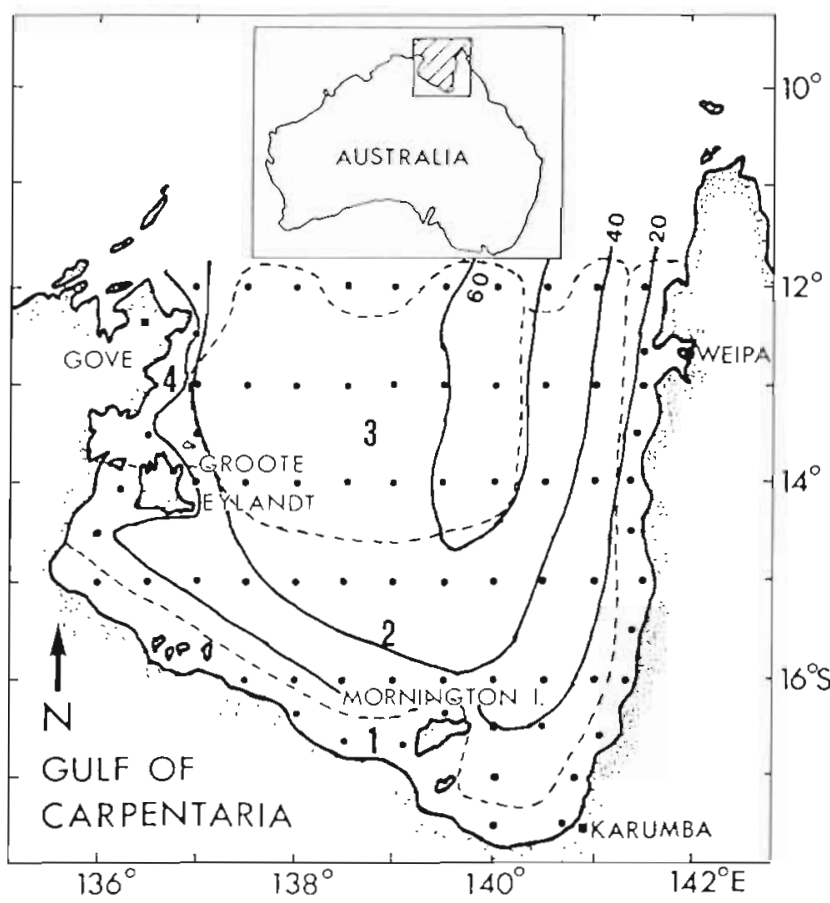

Fig. 1 Gulf of Carpentaria showing sampling sites $(\bullet)$, depth contours (solid lines in $\mathrm{m}$ ) and location groupings identified by Student-Newman-Keuls ANOVA (dashed lines and numbers)

\section{RESULTS}

The numbers of cryptonisci in samples taken under $1 \mathrm{~m}^{2}$ of surface area were distributed randomly (Poisson distribution, 1 parameter distribution) while those expressed as numbers per $\mathrm{m}^{3}$ (volume) were distributed normally ( 2 parameter distribution). Adult bopyrids on their penaeid host were distributed almost randomly (a 1 parameter distribution) (Owens 1988) which means the distribution that precedes the adult distribution must be a 1 parameter distribution to be capable of inducing the final adult distribution. Therefore, only cryptoniscid abundance expressed as no. $\mathrm{m}^{-2}$ were used in the analyses. From 177 samples sorted, an estimated 62014 cryptonisci were present with a mean of 350 per sample (Table 1).

Table 1. Estimates of cryptonisci in samples from 3 Gulf of Carpentaria cruıses

\begin{tabular}{|lrrrrcc|}
\hline & Total & $\begin{array}{c}\text { No. of } \\
\text { samples }\end{array}$ & $\begin{array}{c}\text { Mean no. } \\
\text { sample }\end{array}$ & SD & $\begin{array}{c}\text { Density } \\
\text { (no. } \text { m }^{-2} \text { ) }\end{array}$ \\
\hline June/July 1976 & 15144 & 34 & 445 & 306 & 30 \\
January 1977 & 14420 & 70 & 198 & 202 & 15 \\
March 1977 & 32450 & 73 & 459 & 334 & 46 \\
Total & 62014 & 177 & 350 & & \\
\hline
\end{tabular}

\section{General model}

A step-down linear model of all main effects and all first-order interactions was fitted to the data matrix and it accounted for $80 \%$ of the variability (equivalent to a correlation coefficient of 0.89 ) (Table 2). Of the fitted variables, location, season, and the locationseason interaction accounted for significant $(p<$ $0.001)$ proportions of the variability, accounting for 65 , 25 , and $10 \%$ of the explained variability respectively. Temperature, light, day/night, depth, salinity and the other first-order interactions were not significant $(\mathrm{p}>$ $0.05)$

Table 2. Variability in numbers of cryptonisci accounted for by the general maximum likelihood stepdown linear model (Baker \& Nelder 1978)

\begin{tabular}{|lccc|}
\hline & \multicolumn{3}{c}{ No. of cryptonisci m ${ }^{-2}$} \\
& \% variability & $F$ & $p$ \\
\hline Full model & 80 & 17.32 & 0.0005 \\
Season & 25 & 71.7 & 0.0005 \\
Location & 65.2 & 31.1 & 0.0005 \\
Season $\times$ location & 9.7 & 2.93 & 0.0005 \\
Partitioned variability & 99.9 & & \\
& & & \\
\hline
\end{tabular}


Table 3. Student-Newman-Keuls (SNK) analysis of variance (Zar 1974) on cryptonisci numbers in geographical locations in the Gulf of Carpentaria ( $p<0.05)$

\begin{tabular}{|lrcc|}
\hline Location & $\begin{array}{c}\text { Mean no. of } \\
\text { cryptonisci m }\end{array}$ & SD & $\begin{array}{c}\text { SNK } \\
\text { grouping }\end{array}$ \\
\hline Close inshore, S and E & 14.1 & 18.9 & 1 \\
Offshore S and E & 42.5 & 20.2 & 2 \\
Central Gulf & 64.8 & 49.5 & 3 \\
Northwestern Gulf & 129.4 & 83.9 & 4 \\
\hline
\end{tabular}

The major location groups were identified by a Student-Newman-Keuls analysis of variance (Table 3). The overall trend is for cryptoniscid numbers to increase from southern inshore areas to the northern areas. The location groups progressed with increasing cryptonisci from the close inshore areas of the southern and eastern Gulf (area 1; Fig. 1) the southern-central (area 2) and northern-central Gulf (area 3 ) and the northwestern inshore and northern areas (area 4).

March (autumn) samples had one-and-a-half times as many cryptonisci $\left(46 \mathrm{~m}^{-2}\right)$ as did June-July (winter, $30 \mathrm{~m}^{-2}$ ) samples which in turn had twice as many as January (summer, $15 \mathrm{~m}^{-2}$ ) samples

The season-location interaction showed that most southern inshore and nearshore locations in March had significantly fewer cryptonisci than estimated by season alone or location alone. During June-July, these same locations had significantly more cryptonisci. All central Gulf and northwestern sites had more cryptonisci than expected at all seasons.

\section{Environmental model}

Season and locality were excluded from the analysis to allow factors that characterised season and locality to emerge. In decreasing order of explained variability, temperature by depth, salinity by depth, depth, salinity by light, temperature, salinity and light accounted for $17,14,13$, $12,6,6$ and $4 \%$ of the variability respectively (Table 4). The overall model accounted for $71 \%$ of the variability and was far less efficient than the general model in explaining variability and it greatly reduced the degrees of freedom. Depth and its interactions were the most important and accounted for large amounts of variability with the highest significance levels.
Table 4. Variability in numbers of cryptonisci accounted for by a model of environmental factors

\begin{tabular}{|lccc|}
\hline \multicolumn{4}{c|}{ No. of cryptonisci $\mathrm{m}^{-2}$} \\
& \% variability & $F$ & $\mathrm{p}$ \\
\hline Full model & 71 & 2.97 & 0.0005 \\
Temperature $\times$ depth & 17.1 & 3.65 & 0.0005 \\
Salinity $\times$ depth & 13.8 & 2.61 & 0.005 \\
Depth & 12.5 & 6.83 & 0.0001 \\
Salinity $\times$ light & 12.0 & 2.28 & 0.01 \\
Temperature & 5.9 & 3.22 & 0.01 \\
Salinity & 5.8 & 3.19 & 0.01 \\
Light & 3.6 & 3.75 & 0.01 \\
Partitioned variability & 70.1 & & \\
Total explained variability & 50.2 & & \\
\hline
\end{tabular}

Cryptonisci abundance maximised between 27 and $29.5^{\circ} \mathrm{C}$ (Fig. 2). At higher temperatures the numbers of cryptonisci dropped to one-eighth of those at the peak. The effect of salinity was very peaked compared to temperature (Fig. 2). There was a gradual increase in cryptonisci with salinity except at 33 to $33.5 \mathrm{ppt}$ where a sharp peak of cryptonisci was observed. Above $33.5 \mathrm{ppt}$, the density of cryptonisci dropped precipitously.

The density of cryptonisci increased up to $55 \mathrm{~m}$, almost the deepest areas in the Gulf. Here, cryptoniscid numbers were over $80 \mathrm{~m}^{-2}$ (Fig. 2). At night (no light penetration) cryptoniscid density was moderate. At low levels of light penetration (turbid water) cryptonisci were few. Cryptonisci were most numerous where light penetrated approximately 10 to $15 \mathrm{~m}$ and

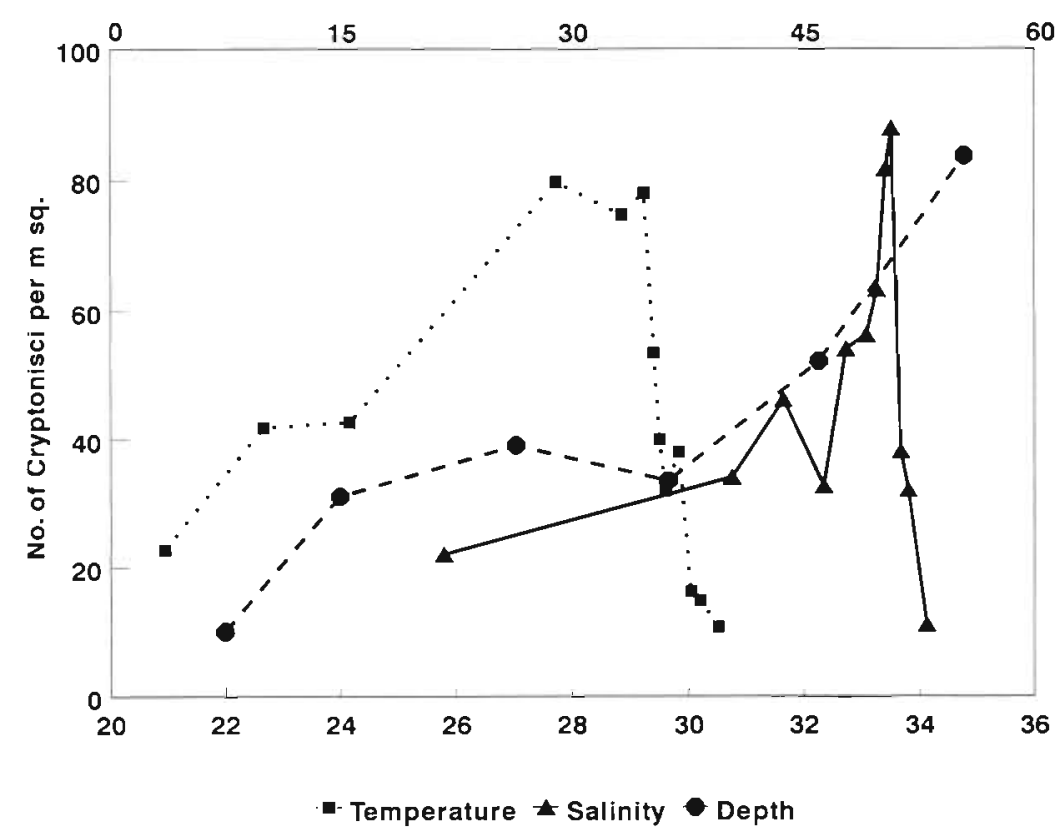

Fig. 2. Relationship between no. of cryptonisci $\mathrm{m}^{-2}$ and temperature, salinity and depth. The scales for temperature $\left({ }^{\circ} \mathrm{C}\right)$ and salinity (ppt) are on the lower $x$-axis and the scale for depth $(m)$ is on the upper $x$-axis 
became less numerous where light penetrated even further.

The interaction terms were difficult to interpret. At mid-range temperatures of 26 to $29^{\circ} \mathrm{C}$, significantly more cryptonisci were found at 10 to $15 \mathrm{~m}$; at temperatures above $29^{\circ} \mathrm{C}$, fewer cryptonisci were found at 10 to $15 \mathrm{~m}$ than expected by depth alone. Although other temperature-depth interactions showed considerable variation, none were significant. There was some variation in salinity by depth; at shallow depths $(8 \mathrm{~m})$ and at salinities between 33 to 33.5 ppt there were significantly fewer cryptonisci than indicated by depth alone or salinity alone. Where light penetrated to $10 \mathrm{~m}$, there were significantly more cryptonisci at 33 ppt than expected by salinity alone or light alone.

\section{Intermediate hosts}

A total of 31 copepods representing 14 different species were collected with cryptonisci or micronisci attached (Table 5). The most common intermediate hosts were Canthocalanus pauper and Paraeuchaeia concinna. Most copepod species only occurred once or twice with cryptonisci attached. All were calanoid copepods except for Oncaea clevei from the suborder Cyclopoida. No harpacticoid copepods found had cryptonisci attached.

In an analysis of 83 species of copepods from a subset of 54 sites, Othman (1986) showed that only 4 species of copepod accounted for $58 \%$ of the variation in cryptonisci abundance. Those species were the 3 calanoid copepods Canthocalanus pauper, Paraeu- chaeta concinna and Metacalanus aurivilli, and the cyclopoid Corycaeus asiaticus. Although analysis of individual months showed some variation, $C$. pauper and $P$. concinna were present in 2 of the 3 cruises and prominent in both regression and direct observation of attached cryptonisci.

Numbers and species of copepods that were examined by Othman (1986) were combined with the general model factors (i.e. season, location, season-location) and then with the environmental factors (i.e. temperature, salinity, depth, light) and reanalysed by ANOVA with covariates (Zar 1974). Only 23 of the 70 Gulf-wide sampling sites examined by Othman (1986) had copepods, environmental information, and cryptonisci. However, in both analyses, the environmental variables were significant and the copepod species were nonsignificant, indicating cryptoniscid abundance was more strongly linked to the environmental factors than copepod numbers.

\section{DISCUSSION}

\section{Environment}

Seasonality of reproduction of bopyrids is determined by 3 main factors: the prevalence of infection, the size of the bopyrid, and the reproductive activity of the bopyrid. The abundance of copepod intermediate hosts in the Gulf shows very little temporal change (Othman 1986) and can be discounted as a limiting factor in reproduction, especially since the main hosts (Canthocalanus pauper and Corycaeus asiaticus) were ubiquitous. The

Table 5. List of copepod species with no. of cryptonisci found attached and multiple regression analysis. I: Inshore species; O: offshore species, U: ubiquitous (Othman 1986)

\begin{tabular}{|c|c|c|c|c|}
\hline Copepod species & Number & $\begin{array}{c}\text { Change in } \mathrm{R} \text { on addition } \\
\text { of copepod species }\end{array}$ & $\begin{array}{l}\text { Partial correlation } \\
\text { coefficient }\end{array}$ & $\begin{array}{l}\text { Copepod } \\
\text { group }\end{array}$ \\
\hline Calanopia elliptica & 1 & & & I \\
\hline Canthocalanus pauper & 10 & 0.59 & 0.32 & $\mathrm{U}$ \\
\hline Centropages furcatus & 1 & & & I \\
\hline Clausocalanus minor? & 1 & & & 0 \\
\hline Corycaeus asiaticus & 0 & 0.09 & 0.20 & $\mathrm{U}$ \\
\hline Eucalanus subcrassus & 2 & & & $\mathrm{U}$ \\
\hline Eucalanus sp. & 2 & & & \\
\hline Eucalanus monachus & 2 & & & \\
\hline Metacalanus aurivilli & 0 & 0.05 & 0.34 & 1 \\
\hline Oncaea clevei & 1 & & & $\mathrm{U}$ \\
\hline Paracalanus aculetus & 1 & & & U \\
\hline Paracalanus elegans & 1 & & & U \\
\hline Paracalanidae 'C' & 3 & & & \\
\hline Paraeuchaeta concinna & 4 & 0.03 & 0.45 & 0 \\
\hline Scolecithricella onentalis & 1 & & & $\mathrm{O}$ \\
\hline Undinula vulgaris & 1 & & & $\mathrm{O}$ \\
\hline Total & 31 & & & \\
\hline
\end{tabular}


period of peak prevalence of Epipenaeon ingens on Penaeus semisulcatus was April to June (Owens \& Glazebrook 1985). Size increased over the calendar year with reproduction starting in January-February and individuals produced more larvae as their size increased. However, cooler water temperatures during winter depress the spawning activity of the bopyrid (Owens \& Glazebrook 1985). January had the lowest number of cryptonisci because most bopyrids were just coming into reproductive activity. By March, prevalence was rising, bopyrids were larger and reproductive activity was high. In June-July, prevalence was higher than in March but falling rapidly, size was still increasing but due to cooler water temperatures reproductive activity was low (Owens \& Glazebrook 1985). This is reflected by a lower number of cryptonisci than in March, suggesting reproductive activity to be the most important component to reproductive output. Similarly, Greenwood (1980) found peak abundance of cryptonisci in Moreton Bay, Australia, in autumn (early May) and again in spring (November) with the November peak being twice as large as the May peak.

One of the most important environmental variables associated with cryptoniscid abundance was depth and its interactions. The location boundaries roughly follow the depth contour lines with greater numbers of cryptonisci being found in deeper water, especially $>40 \mathrm{~m}$. Paradoxically, while cryptonisci are in deep water, prawn postlarvae become infected in shallow water nursery areas (sea grass beds in the case of Penaeus semisulcatus; Owens \& Glazebrook 1985). The area north of Groote Eylandt where deep water is relatively close inshore, thus increasing the probability of cryptonisci successfully finding postlarval prawns close to the neighbouring nursery grounds, is a site of high prevalence of bopyrids on $P$. semisulcatus.

Penaeus semisulcatus is the main host for Epipenaeon ingens in the Gulf of Carpentaria. Adult $P$. semisulcatus have a preference for deeper water with $97 \%$ of the population captured in waters $>20 \mathrm{~m}$ in depth and almost one-third at depths $>40 \mathrm{~m}$ (Somers et al. 1987). This may in part explain the strong correlations between depth and cryptoniscid number and probably explains why the southern and eastern Gulf coastline areas, which are less than $20 \mathrm{~m}$ in depth, have few cryptonisci. Furthermore, in November, the southeastern corner has salinity $>36.5 \mathrm{ppt}$ and temperature $>30^{\circ} \mathrm{C}$ (Anon 1977), both of which were associated with low numbers of cryptonisci. In fact, the whole eastern area of the Gulf is characterised at this time of the year by temperatures $>30^{\circ} \mathrm{C}$ which appear unfavourable to cryptonisci and hence contribute to low numbers.

Low numbers of bopyrid cryptonisci in the southern inshore Gulf are associated with seasonal advection.
Directions of advection for vertically migrating larvae are different at different times of the year. In March, the advection direction is northwards, whilst in October, it is southwards (Rothlisberg et al. 1983). Cryptonisci would follow this scheme (Owens \& Rothlisberg 1991), and this may account for the location-season interaction, with fewer numbers of cryptonisci inshore during March. It also suggests that by July the advection direction may be inshore as shown by greater numbers of cryptonisci in that area at that time.

\section{Intermediate hosts}

Othman (1986) showed that the copepod fauna of the Gulf of Carpentaria is divided into offshore, intermediate and inshore faunas. We found these faunal groups had highly significant differences in depth across all 3 cruises analysed. A temperature effect was very highly significant $(p<0.001)$ across fauna groups in January and highly significant $(\mathrm{p}<0.01)$ in June-July and March whilst a salinity effect was highly significant $(p<0.01)$ in June-July and March but not significant in January $(p>0.05)$. Both cryptonisci and copepods seem to respond to the same environmental variables with the same order of importance and this explains why environmental factors exceed the availability of copepod intermediate hosts as a determinant of cryptonisci abundance.

There was good agreement between the copepods found with cryptonisci attached and those possible intermediate hosts indicated by multiple regression analysis, at least in the most important species, Canthocalanus pauper and Paraeuchaeta concinna. These differed markedly from those copepod species implicated as intermediate hosts during a study of vertical migration of cryptonisci (Owens \& Rothlisberg 1991) with only 1 species being shared, Calanopia elliptica. In the vertical migration study, C. elliptica had the largest simple regression coefficient with cryptoniscid numbers, but it was displaced by depth in a multiple regression analysis. The Mornington Island, Australia, site for the vertical migration study was a relatively high density area for cryptonisci characterised by inshore species of copepods (Othman 1986). In Owens \& Rothlisberg (1991), 5 of the 8 copepods recorded were inshore species, and 10 of 13 classifiable copepods listed in this study (Table 5) were ubiquitous or offshore species (Othman 1986). In the present study, most cryptonisci were found in offshore habitats. Therefore, the inshore species of copepods could have been masked by the greater abundance of the offshore species.

A further consequence of the use of ubiquitous offshore species of copepods as intermediate hosts was 
the spread of cryptonisci throughout the whole Gulf. Spawning Penaeus semisulcatus, as indicated by protozoeal larvae, were found in depths greater than $40 \mathrm{~m}$ (Rothlisberg et al. 1987) and possibly some parasitised $P$. semisulcatus might also be present there, although Somers \& Kirkwood (1991) found that most of the parasitised population (median depth $27 \mathrm{~m}$ ) does not migrate as far into the deep waters as the unparasitised population (median depth $40 \mathrm{~m}$ ). Released epicaridium larvae of the bopyrids would have no trouble finding ubiquitous copepod intermediate hosts to develop to cryptonisci. Whether these cryptonisci contribute to the next bopyrid generation or not is undetermined but the consequent dispersive powers of the bopyrid are considerably larger than first expected (Owens \& Rothlisberg 1991).

Acknowledgements. All aspects of the field work were assisted by C. J. Jackson and R. C. Pendrey whose help is gratefully acknowledged. Sincere thanks to Dr J. Greenwood for the identification of the copepods infected with cryptonisci and for a copy of B. H. R. Othman's thesis. This study was funded in part by a Marine Science and Technology Grant to L.O.

\section{LITERATURE CITED}

Anderson G, Dale WE (1981) Probopyrus pandalicola (Packard) (Isopoda, Epicaridea): morphology and development of larvae in culture. Crustaceana 41:143-161

Anon (1977) Gulf of Carpentaria prawn fishery is complex and intriguing. Aust Fish 36(6):4-11

Baker RJ, Nelder JA (1978) The GLIM system. Royal Statistical Society, Oxford

Beck JT (1979) Population interactions between a parasitic castrator, Probopyrus pandalicola (Isopoda: Bopyridae), and one of its freshwater shrimp hosts, Palaemonetes paludosus. Parasitology 79(3):431-449

This article was submitted to the editor
Beck JT (1980) The effects of an isopod castrator, Probopyrus pandalicola, on the sex characters of one of its caridean shrimp hosts, Palaemonetes paludosus. Biol Bull 158:1-15

Caroli E (1928) La fase 'micronisci' di Ione thoracica (Mont.) ottenuta per allevamento sui copepodi. Accademia Nazionale dei Lincci Rendiconti ser 6, 8:321-326

Greenwood JG (1980) Composition and seasonal variations of zooplankton populations in Moreton Bay, Queensland. Proc R Soc Qld 91:85-103

Othman BHR (1986) Copepods of the Gulf of Carpentaria PhD thesis, Univ of Queensland, Brisbane

Owens L (1988) Are bopyrids capable of regulating populations of Penaeus semisulcatus? International Oceanographic Commission/WESTPAC Symposium on the Indo Pacific Convergence. Townsville

Owens L, Glazebrook JS (1985) The biology of bopyrid isopods parasitic on commercial penaeid prawns in northern Australia, In: Rothlisberg PC, Hill BJ, Staples DJ (eds) Second Aust Nat Prawn Sem. NPS2, Cleveland, Australia, p $105-113$

Owens L, Rothlisberg PC (1991) Vertical migration and advection of bopyrid cryptoniscid larvae in the Gulf of Carpentaria, Australia. J Plankton Res 13:779-787

Rothlisberg PC, Church JA, Forbes AMG (1983) Modelling the advection of vertically migrating shrimp larvae. $J$ mar Res 41:511-538

Rothlisberg PC, Jackson CJ, Pendrey RC (1987) Larval ecology of penaeids of the Culf of Carpentaria, Australia. I. Assessing the reproductive activity of five species of Penaeus from the distribution and abundance of the zoeal stage. Aust J mar Freshwat Res 38:1-17

Somers IF, Kirkwood GP (1991) Population ecology of the grooved tiger prawn. Penaeus semisulcatus in the northwestern Gulf of Carpentaria: growth movement, age structure and infestation by the bopyrid parasite Epipenaeon ingens. Aust J mar Freshwat Res 42:349-367

Somers IF, Crocos PJ, Hill BJ (1987) Distribution and abundance of the tiger prawns Penaeus esculentus and $P$. semisulcatus in the north-western Gulf of Carpentaria, Australia. Aust $J$ mar Freshwat Res 38:63-78

Zar JH (1974) Biostatistical analysis. Prentice Hall, Englewood Cliffs, NJ

Manuscript first received: October 7, 1994

Revised version accepted: February 8, 1995 